\title{
Activation of $\beta 2$-adrenoceptor enhances synaptic potentiation and behavioral memory via cAMP-PKA signaling in the medial prefrontal cortex of rats
}

\author{
Hou-Cheng Zhou, ${ }^{1}$ Yan-Yan Sun, ${ }^{1}$ Wei Cai, ${ }^{1}$ Xiao-Ting He, ${ }^{1}$ Feng Yi, ${ }^{1}$ Bao-Ming Li, ${ }^{1,2,3}$ \\ and Xue-Han Zhang ${ }^{1,3}$ \\ ${ }^{1}$ Institute of Neurobiology and State Key Laboratory of Medical Neurobiology, Institutes of Brain Science, Fudan University, Shanghai \\ 200032, China; ${ }^{2}$ Center for Neuropsychiatric Diseases, Institute of Life Science, Nanchang University, Nanchang 330031, China
}

\begin{abstract}
The prefrontal cortex (PFC) plays a critical role in cognitive functions, including working memory, attention regulation, behavioral inhibition, as well as memory storage. The functions of PFC are very sensitive to norepinephrine (NE), and even low levels of endogenously released NE exert a dramatic influence on the functioning of the PFC. Activation of $\beta$-adrenoceptors ( $\beta$-ARs) facilitates synaptic potentiation and enhances memory in the hippocampus. However, little is known regarding these processes in the PFC. In the present study, we investigate the role of $\beta 2$-AR in synaptic plasticity and behavioral memory. Our results show that $\beta 2$-AR selective agonist clenbuterol facilitates spike-timing-dependent long-term potentiation (tLTP) under the physiological conditions with intact GABAergic inhibition, and such facilitation is prevented by co-application with the cAMP inhibitor Rp-cAMPS. Loading postsynaptic pyramidal cells with Rp-cAMPS, the PKA inhibitor $\mathrm{PKI}_{5-24}$, or the $\mathrm{G}$ protein inhibitor GDP- $\beta-S$ significantly decreases, but does not eliminate, the effect of clenbuterol. Clenbuterol suppresses the GABAergic transmission, while blocking GABAergic transmission by the $\mathrm{GABA}_{\mathrm{A}}$ receptor blocker partially mimics the effect of clenbuterol. In behavioral tests, a post-training infusion of clenbuterol into $\mathrm{mPFC}$ enhances 24-h trace fear memory. In summary, we observed that prefrontal cortical $\beta 2-A R$ activation by clenbuterol facilitates tLTP and enhances trace fear memory. The mechanism underlying tLTP facilitation involves stimulating postsynaptic cAMP-PKA signaling cascades and suppressing GABAergic circuit activities.
\end{abstract}

[Supplemental material is available for this article.]

The prefrontal cortex (PFC) plays a critical role in several aspects of cognition, including attention regulation, behavioral inhibition, learning, and memory (Goldman-Rakic 1987; Miller and Cohen 2001; Fuster 2003). The PFC guides behavior and thought using working memory (Goldman-Rakic 1987) and is involved in the encoding and retrieval of memories, such as the inhibition of proactive interference and the prevention of memories and thoughts from becoming distracting. Additionally, the PFC participates in the association of temporally separated events (Fuster et al. 2000) and the long-term storage of information involving temporal relationships (Runyan et al. 2004). Damage to the PFC results in an inability to select, maintain, and associate temporally disconnected stimuli (Dias et al. 1997).

Norepinephrine (NE), a neuromodulatory transmitter, is secreted in response to arousing or novel stimuli (Sara and Segal 1991; Berridge and Waterhouse 2003). The release of low to moderate levels of NE activates $\alpha$-2A adrenoceptors and improves PFC functions, such as working memory performance and attention (Arnsten and Goldman-Rakic 1985; Arnsten et al. 1988; Franowicz and Arnsten 1998; Li et al. 1999; Franowicz et al. 2002; Wang et al. 2007). By contrast, higher levels of NE, as well as stress, activate $\alpha-1$ adrenoceptors and impair PFC functions (Arnsten and Jentsch 1997; Birnbaum et al. 1999; Mao et al. 1999; Marzo et al. 2010).

\footnotetext{
${ }^{3}$ Corresponding authors

E-mail xuehanzhang@fudan.edu.cn

E-mail bmli@ncu.edu.cn

Article is online at http://www.learnmem.org/cgi/doi/10.1101//m.030411.113.
}

$\beta$-Adrenoceptors ( $\beta$-ARs) are G-protein-coupled receptors that mediate physiological responses to NE. $\beta$-ARs include three subtypes, $\beta 1, \beta 2$, and $\beta 3$, which are all present in the nervous system. Extensive behavioral and physiological studies have demonstrated that $\beta$-AR activation facilitates long-term potentiation (LTP) (Katsuki et al. 1997; Lin et al. 2003; Straube et al. 2003; Gelinas and Nguyen 2005; O'Dell et al. 2010; Connor et al. 2011) and enhances memory (Ji et al. 2003; Tronel et al. 2004; Lemon et al. 2009; Miranda et al. 2011).

The stimulation of $\beta 2$-AR has been shown to enhance LTP and memory in the hippocampus and amygdala. For example, Qian et al. (2012) reported that $\beta 2$-AR activation supports prolonged hippocampal $\theta$-tetanus-LTP (Qian et al. 2012), which is an important form of synaptic plasticity for hippocampal functions. McGaugh and co-workers (1991) reported that the infusion of the $\beta 2$-AR agonist clenbuterol into the amygdala immediately after training enhances memory retention in an inhibitory avoidance task (Introini-Collison et al. 1991). By contrast, the functions of prefrontal cortical $\beta 2$-AR in synaptic plasticity and behavioral memory, particularly the cellular mechanisms involved in these functions, remain poorly studied.

Excitatory glutamatergic synapses in the PFC are plastic, and changes in synaptic strength occur in the PFC during behavioral tasks, particularly during working-memory-related tasks (Laroche et al. 1990; Jay et al. 1995). Changes in the strength of cortical synapses are presumed to occur depending on the precise timing of pre- and postsynaptic activity, a process known as spike-timing-dependent plasticity (Magee and Johnston 1997; Markram et al. 1997; Bi and Poo 2001). The relative timing 
of pre- and postsynaptic activity determines whether synaptic strength will increase or decrease (Sjostrom and Nelson 2002). Therefore, prefrontal cortical spike-timing-dependent plasticity has been proposed as an important cellular mechanism underlying PFC cognitive functions.

Trace conditioning is a form of learning that requires the association of a conditioned stimulus (CS) and an unconditioned stimulus (US) separated by time, which differs from the classic delay paradigm in that the animal must sustain attention during the trace interval to learn the CS-US association (Huerta et al. 2000; Han et al. 2003). The PFC has been proposed to be involved in the acquisition and the storage of trace fear memory (Sacchetti et al. 2002; Runyan et al. 2004; Gilmartin and McEchron 2005). Synaptic plasticity within the $\mathrm{mPFC}$ is critical for the storage of trace fear memory (Gilmartin and Helmstetter 2010). However, the effect of $\mathrm{mPFC}$ noradrenergic modulation on trace fear memory remains unknown.

The present study aimed to characterize the effect of prefrontal cortical $\beta 2$-AR activation on synaptic potentiation and behavioral memory. We examined the effect of the $\beta 2$-AR agonist clenbuterol on spike-timing-dependent LTP (tLTP) using an in vitro whole-cell patch-clamp recording technique. Furthermore, we examined the effect of injecting clenbuterol directly into rats' mPFC immediately after trace fear conditioning. The results from both studies suggest that the activation of $\beta 2$-AR by clenbuterol enhances tLTP and memory retention and that these enhancements can be reversed by the $\beta 2$-AR antagonist ICI 118551.

\section{Results}

\section{The $\beta 2-A R$ is present in pyramidal cells of the $\mathrm{mPFC}$}

$\beta 2$-AR expression in the PFC of humans (Kalaria et al. 1989) and nonhuman primates (Flugge et al. 1997) has been extensively investigated. However, the distribution of $\beta 2$-AR in the rodent PFC is unknown. We examined the expression of $\beta 2$-AR in pyramidal cells of the rat PFC using a double immunofluorescence labeling technique. CaMKII is a pyramidal cell marker (Muller et al. 2006). Confocal images showed that $\beta 2$-AR is expressed uniformly in pyramidal cells of both superficial layers (layer 2/3) and deep layers (layer 5/6) of mPFC. Figure 1 shows that nearly all CaMKIIpositive cells stained positively for $\beta 2-\mathrm{AR}$, which indicates that $\beta 2$-AR is widely present in pyramidal cells of the $\mathrm{MPFC}$.

\section{The activation of the $\beta 2-A R$ facilitates tLTP}

The wide distribution of $\beta 2$-AR in the pyramidal cells of the mPFC implies that $\beta 2$-AR has an important role in physiological function. Therefore, we inquired whether activation of $\beta 2$-AR could alter the synaptic plasticity of the mPFC. To test this question, we performed whole-cell patch-clamp recordings from visually identified pyramidal neurons in layer $2 / 3$ of the mPFC slices and stimulated input by extracellular stimulation in layer $2 / 3$ (Fig. 2A). We identified pyramidal cells by injecting depolarized currents into the neurons to induce action potentials. The typical firing pattern of the pyramidal cells showed significant firing frequency adaptations (Tsvetkov et al. 2002) (Fig. 2B, left). The injection of lucifer yellow into the intracellular solution allowed us to identify pyramidal cells based on the pyramid shape of their somata and their apical dendrites (Fig. 2B, right).

LTP was induced by spike-timing protocol (Fig. 2A) under intact GABAergic inhibition. The repeated pairing of the EPSP with a single postsynaptic action potential $(10 \mathrm{msec}$ after the start of the EPSP, $50 \times$ at $0.1 \mathrm{~Hz}$ ) resulted in a lasting increase of both EPSP amplitude and slope under the intact GABAergic inhibition (mean = $111.11 \pm 3.90 \%$ of baseline, $n=7$ cells from seven rats, paired
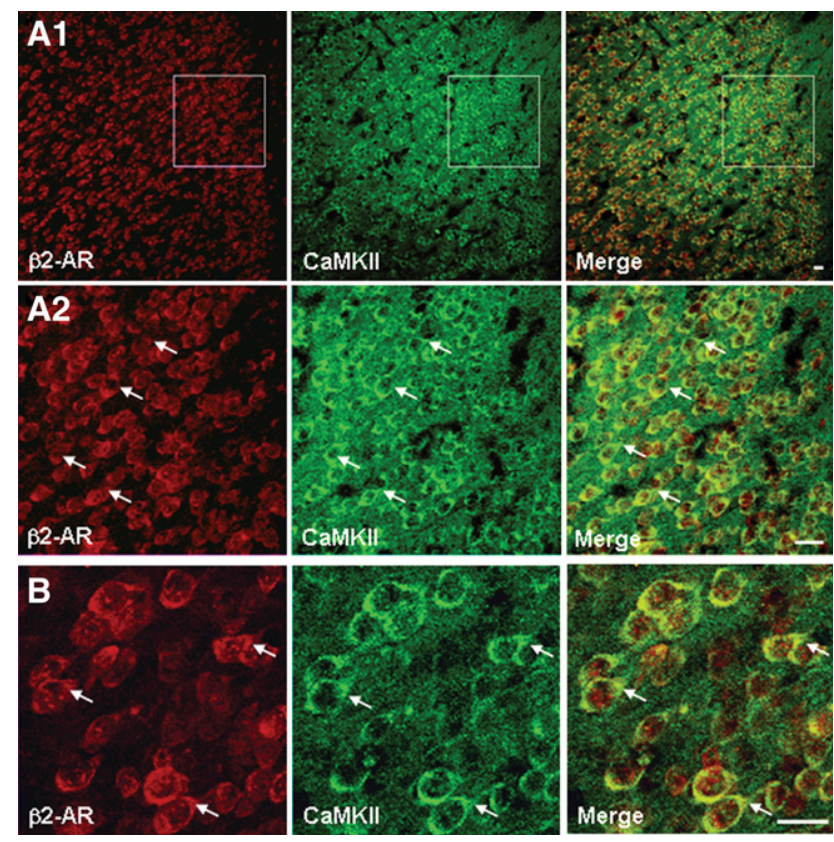

Figure 1. $\beta 2-A R$ is present in pyramidal cells of the mPFC. Microscopic confocal images showing that $\beta 2$-AR is co-expressed with CaMKII in mPFC cells. The images are double stained with $\beta 2-A R$ (red) and CaMKII (green). (A1) Each square illustrates a section of layer $2 / 3$ cells at a low magnification. The images from the boxed areas in $A 1$ are shown in $A 2$. (B) The images at a higher magnification. The arrowheads indicate doublelabeled cells. Bars, $20 \mu \mathrm{m}$.

t-test, $P<0.05$ vs. the baseline response before the spike-timing pairing) (Fig. 2C).

When clenbuterol $(10 \mu \mathrm{M})$, a $\beta 2$-AR selective agonist, was applied during the pairing period (from $1 \mathrm{~min}$ before through +7 min after the start of the 8-min pairing protocol), tLTP was enhanced significantly (mean $=154 \pm 6.45 \%$ of baseline, $n=7$ cells from six rats, $t$-test, $P<0.01$ vs. controls) (Fig. $2 D$ ). tLTP enhancement was eliminated with the co-application of clenbuterol and ICI $118551(10 \mu \mathrm{M})$, a $\beta 2$-AR selective antagonist $($ mean $=$ $114.22 \pm 5.64 \%$ of baseline, $n=6$ cells from six rats, $t$-test, $P>$ 0.05 vs. controls) (Fig. 2E). Thus, the activation of $\beta 2$-AR enhances tLTP in the layer $2 / 3$ pyramidal cells of the mPFC.

\section{tLTP facilitation induced by $\beta 2-A R$ activation involves cAMP-PKA signaling}

We also investigated whether clenbuterol-induced tLTP facilitation was mediated by Gs-cAMP-PKA signaling, the classic downstream signaling pathway of $\beta 2$-AR. Co-application of the membrane-permeable cAMP inhibitor Rp-cAMPS $(20 \mu \mathrm{M})$ with clenbuterol during the pairing period prevented tLTP (127.23 \pm $4.47 \%$ of the baseline, $n=5$ cells from four rats, $P>0.05$ vs. the baseline response) (Fig. 3A). Importantly, loading membraneimpermeable cAMP inhibitor Rp-cAMPS $(100 \mu \mathrm{M})$, membrane-impermeable protein kinase A (PKA) inhibitory peptide $\mathrm{PKI}_{5-24}(0.5$ $\mu \mathrm{M})$, or G-protein inhibitor GDP- $\beta-S(1 \mathrm{mM})$ in the recording pipette significantly decreased clenbuterol-induced tLTP facilitation compared to that in the clenbuterol group (Rp-cAMPS, $127.23 \pm$ $4.47 \%$ of baseline, $n=5$ cells from four rats; $\mathrm{PKI}_{5-24}, 128.49 \pm$ $6.62 \%$ of baseline, $n=5$ cells from five rats; GDP- $\beta-S, 129.36 \pm$ $5.76 \%$ of baseline, $n=4$ from four rats, $P<0.05$ vs. clenbuterol group) (Fig. 3), but did not eliminate the facilitation compared to the control group ( $P<0.05$ vs. the control group). These results suggest that postsynaptic cAMP-PKA signaling is involved in tLTP 
A

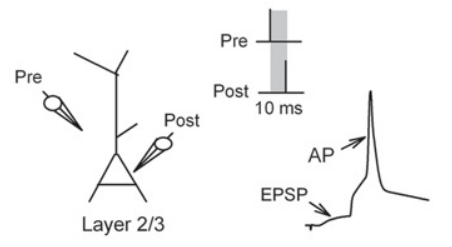

B

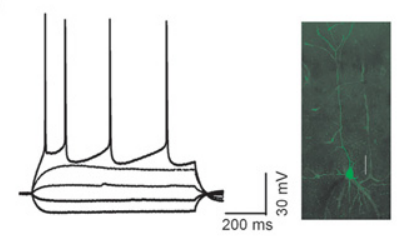

C

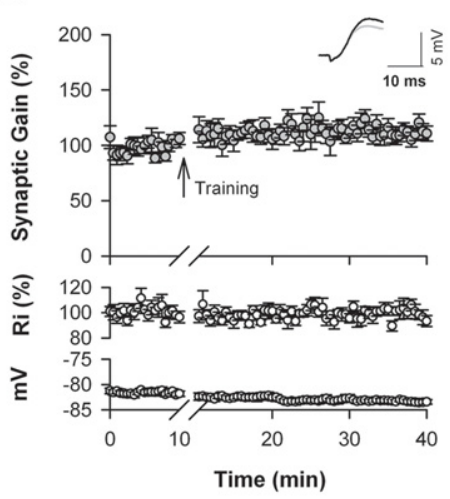

E
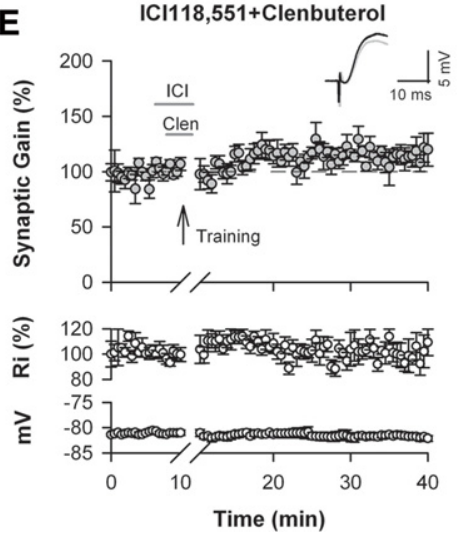

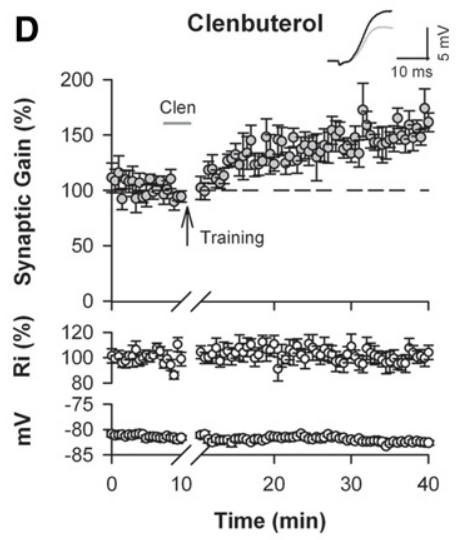

$\mathbf{F}$

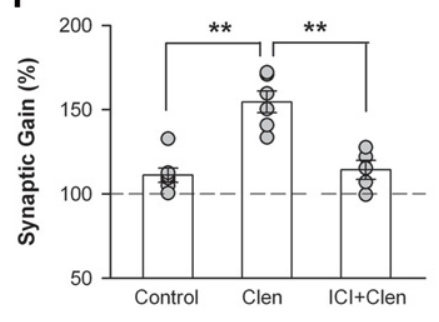

highly susceptible to GABAergic inhibition (Meredith et al. 2003; Campanac and Debanne 2008). Thus, we investigated whether clenbuterol enhanced tLTP by affecting GABAergic transmission. To test this question, we recorded spontaneous inhibitory postsynaptic currents (sIPSCs) in the presence of DNQX (20 $\mu \mathrm{M})$ and APV $(50 \mu \mathrm{M})$, which blocked AMPA-receptor and NMDA-receptor-mediated excitatory transmissions, respectively. Seven to ten minutes after the application of clenbuterol $(10 \mu \mathrm{M})$, the frequency of sIPSC was reduced to $70.14 \pm 2.97 \%$ of the baseline $(P<0.01$ vs. baseline, $n=7$ cells from six rats) (Fig. 4A) and the amplitude was decreased to $74.22 \pm 5.97 \%$ of baseline ( $P$ $<0.01$ vs. baseline) (Fig. 4A). The suppression effect of clenbuterol on SIPSC was largely recovered 7-10 $\mathrm{min}$ after the termination of the clenbuterol application (frequency, $96.27 \pm 8.96 \%$ of baseline; amplitude, $92.35 \pm 10.42 \%$ of baseline, data not shown) (Fig. 4A). sIPSC response depends on action potential firing.

In addition, we tested the effect of clenbuterol on evoked GABAergic transmission. The eIPSCs resulting from the stimulation of layer $2 / 3$ were completely blocked by the GABAa receptor antagonist, $50 \mu \mathrm{M}$ picrotoxin (Fig. 4B). Seven to ten minutes after the application of clenbuterol, the eIPSC amplitude significantly decreased to $73.92 \pm 6.16 \%$ of baseline $(P<0.01$ vs. baseline, paired $t$-test, $n=7$ cells from seven rats). $R_{\mathrm{i}}$ remained unchanged during the clenbuterol application $\left(R_{\mathrm{i}}, 101.77 \pm 1.36 \%\right.$ of baseline for 7-10 min of clenbuterol application, data not shown). The suppression effect on the eIPSCs tended to recover 7-10 min after the termination of the clenbuterol application (89.89 \pm $4.54 \%$ of baseline, data not shown). Furthermore, we examined the effect of clenbuterol in the continuous presence of the $\beta 2$-AR antagonist ICI118,551 $(10 \mu \mathrm{M})$. Under this condition, the clenbuterol suppression of eIPSC no longer existed (Fig. 4B). The eIPSC amplitude under clenbuterol treatment was $96.91 \pm 4.16 \%$ baseline $(P>0.05$ vs. baseline, paired $t$-test, $n=7$ cells from five rats), indicating that the clenbuterol suppression was mediated by $\beta 2$-ARs but

facilitation induced by clenbuterol and indicate that clenbuterol can act on both pre- and postsynaptic $\beta 2$-AR to enhance tLTP.

\section{The activation of $\beta 2-A R$ suppresses GABAergic input to pyramidal cells}

Pyramidal cells in the mPFC receive glutamatergic and GABAergic inputs. The induction of tLTP under intact inhibitory circuits is not by nonspecific mechanisms.
whether the suppression effect of clenbu-

We then inquired whether the suppression effect of clenbu-
on GABAergic transmission occurred through the reduction of presynaptic GABA release. To investigate this question, we examined the effect of clenbuterol on mIPSCs, which are action potential independent and represent the responses of pyramidal cells to spontaneous releases of single GABA-containing vesicles. In the present study, mIPSCs were recorded in the presence of 0.5 $\mu \mathrm{M}$ tetrodotoxin, which blocks action potential firing and 

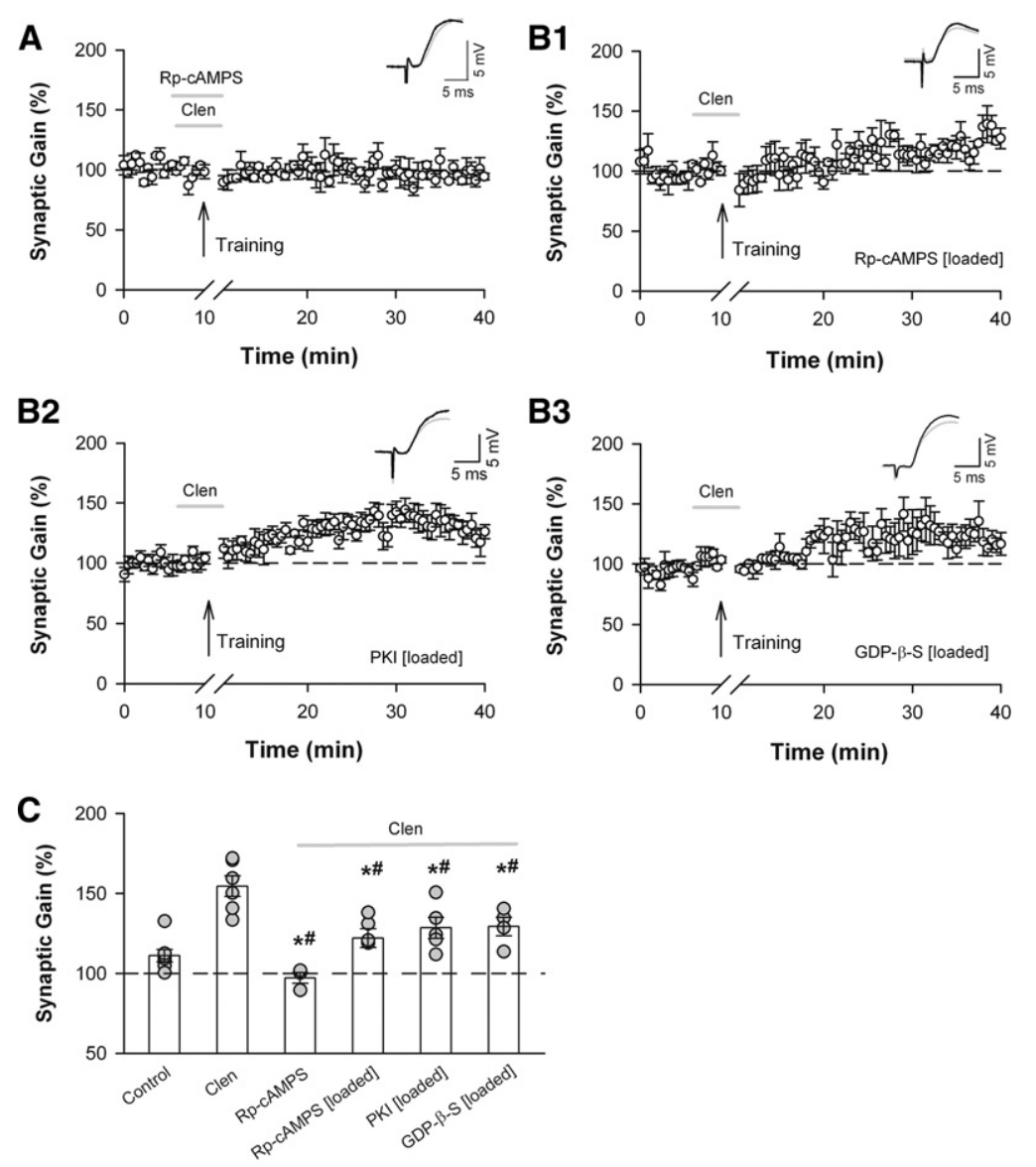

Figure 3. The activation of $\beta 2-A R$ enhances tLTP via CAMP-PKA signaling. (A) The co-application of clenbuterol with permeable cAMP inhibitor Rp-CAMPS prevents tLTP. (B) Clenbuterol-potentiated tLTP is significantly decreased but not completely eliminated by recording pipette-loaded Rp-cAMPS $\left(\right.$ Rp-CAMP $\left.{ }_{(\text {loaded })}\right)(B 1), \mathrm{PKI}_{5-24}\left(\mathrm{PKI}_{\text {(loaded) }}\right)(B 2)$, and GDP- $\beta-S\left(G D P-\beta-S_{\text {(loaded) }}\right)(B 3)$. (C) A summary of tLTP. $\left({ }^{*}\right) P<0.05$ vs. the clenbuterol group, $\left({ }^{\#}\right) P<0.05$ vs. the control group.

(frequency, $97.21 \pm 2.89 \%$ of baseline, $P>0.05$ vs. controls; amplitude, $101.56 \pm 2.71 \%$ of baseline, $P>0.05$ vs. controls; $n=7$ cells from six rats). We further examined the effect of clenbuterol on evoked synaptic response. Figure $5 \mathrm{~B}$ shows that clenbuterol has no effect on both the amplitude of evoked EPSC (eEPSC) and the slope of evoked EPSP (eEPSP) (eEPSC, $97.53 \pm$ $3.64 \%$ baseline, $P>0.05$ vs. controls, $n=8$ from seven rats; eEPSP, $100.11 \pm$ $8.9 \%$ baseline, $P>0.05$ vs. controls, $n=7$ cells from four rats). These results suggest that the activation of $\beta 2$-AR did not alter the excitatory glutamatergic input to the pyramidal cells.

\section{The suppression of GABAergic transmission partially mimics the effect of $\beta 2-A R$ activation on tLTP} tLTP induction at many excitatory synapses is sensitive to GABAergic inhibition (Meredith et al. 2003; Campanac and Debanne 2008). The presented data show that activation of $\beta 2$-AR suppresses GABAergic transmission. Then, we ask whether the reduction of GABAergic transmission plays a dominant role in tLTP facilitation induced by $\beta 2$-AR activation. To test this question, we added $\mathrm{GABA}_{\mathrm{A}}$ receptor blocker picrotoxin $(50 \mu \mathrm{M})$ in the perfusion artificial cerebrospinal fluid (ACSF) to block the GABAergic inhibitory circuit. Figure 6 shows that tLTP was induced in the presence of picrotoxin (mean $=124.26 \pm$ $3.61 \%$ of baseline, $n=5$ cells from four rats, paired $t$-test, $P<0.05$ vs. the base-

propagation. Figure $4 \mathrm{C}$ shows that during a $7-10$ min bath application of clenbuterol, the mIPSC frequency decreased to $74.92 \pm$ $3.36 \%$ of baseline ( $P<0.01$ vs. controls) (Fig. $4 \mathrm{~B}$, middle) and mIPSC amplitude decreased to $82.83 \pm 2.02 \%$ of baseline $(P<$ 0.01 vs. controls, paired $t$-test, $n=8$ cells from eight rats) (Fig. $4 \mathrm{~B}$, right). The suppression effect of clenbuterol on mIPSCs was largely washed out after the termination of the clenbuterol application (frequency, $90.60 \pm 5.38 \%$ of baseline; amplitude, $92.07 \pm 3.78 \%$ of controls, data not shown). These data suggest that clenbuterol acts on both pre- and postsynaptic $\beta 2$-AR to suppress GABAergic transmission.

Taken together, these results demonstrate that clenbuterol suppresses inhibitory input into layer $2 / 3$ pyramidal cells by acting on $\beta 2$-AR in both postsynaptic pyramidal cells and presynaptic GABAergic terminals.

\section{The activation of $\beta 2-A R$ has no effect on glutamatergic transmission to pyramidal cells}

Clenbuterol may also enhance tLTP through enhancing the excitatory synaptic input into layer $2 / 3$ pyramidal cells. To investigate this mechanism, we recorded spontaneous excitatory postsynaptic currents (sEPSCs) in the presence of picrotoxin $(50 \mu \mathrm{M})$ to block $\mathrm{GABA}_{\mathrm{A}}$-mediated inhibitory transmission. Figure $5 \mathrm{~A}$ shows that both the frequency and amplitude of sEPSCs remained unchanged 7-10 min after the application of clenbuterol $(10 \mu \mathrm{M})$ line) (Fig. 6A) response before the spike-timing pairing and tLTP magnitude was augmented significantly comparing with the controls, suggesting that GABAergic inhibition constrains tLTP in layer $2 / 3$ pyramidal cells of mPFC ( $P<0.05$ vs. controls) (Fig. $6 \mathrm{~B})$. Moreover, the magnitude of tLTP in the presence of picrotoxin dramatically lowered the magnitude of tLTP induced by clenbuterol ( $P<0.01$ vs. clenbuterol group) (Fig. 6B), suggesting that suppression of GABAergic transmission partially but not completely mimics the effect of clenbuterol on tLTP. Together our data indicate that tLTP enhancement induced by $\beta 2$-AR activation under intact inhibitory circuit is partially mediated by suppressing GABAergic inhibition.

\section{Post-training activation of $\beta 2$-AR enhances trace fear memory in the mPFC}

Synaptic plasticity within the cortex is critical for trace fear memory (Gilmartin and Helmstetter 2010). LTP enhancement in layer $2 / 3$ pyramidal cells of the cortex has been proposed to correspond with enhancement in trace fear conditioning (Wu et al. 2008). Thus, the enhancement of tLTP induced by clenbuterol may lead to an improved retention of trace fear memory. Therefore, we bilaterally infused clenbuterol $(1 \mu \mathrm{g}$ in $0.5 \mu \mathrm{L}$ saline on each side) into the prelimbic (PrL) area of the mPFC immediately posttraining to examine the freezing response in a trace fear memory behavioral task. 


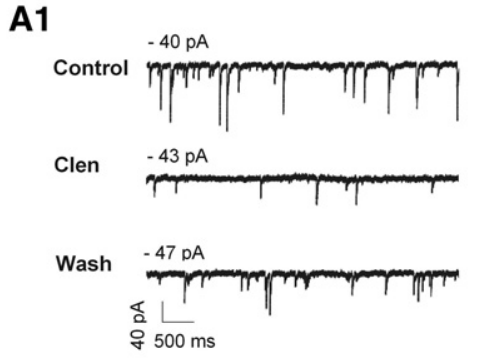

A2

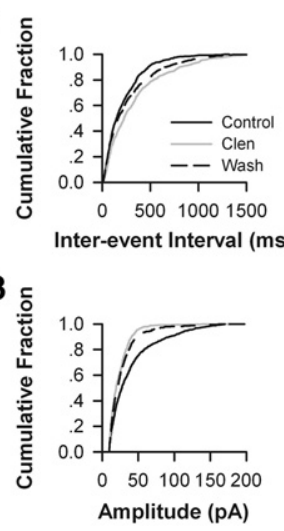

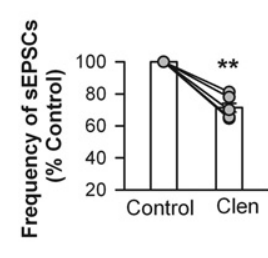

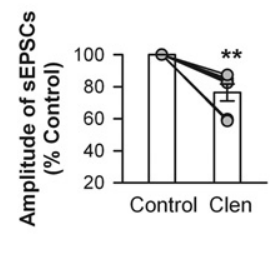

B
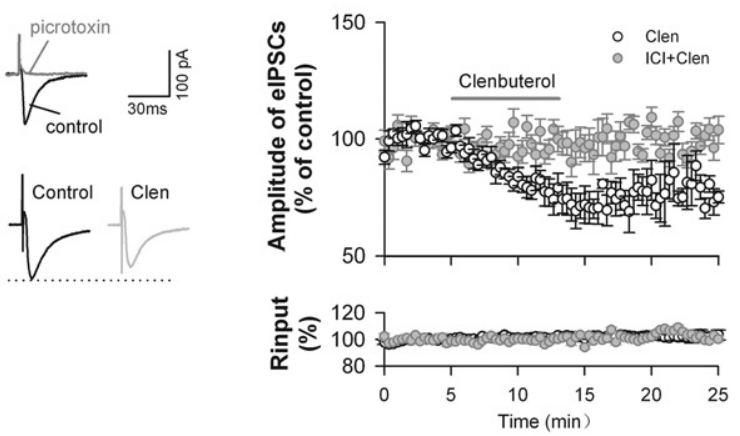

C1

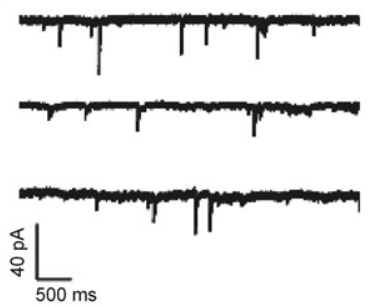

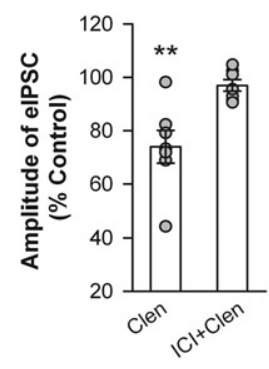
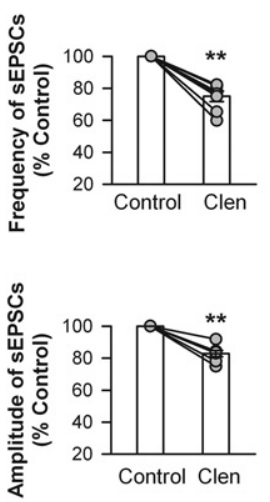

C2

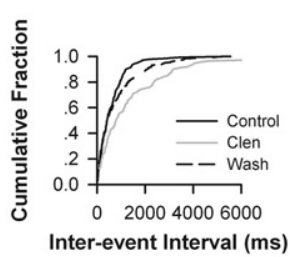

C3

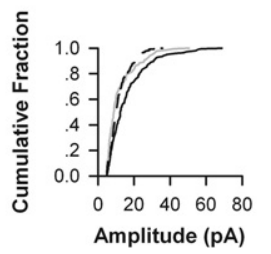

Figure 4. The activation of $\beta 2-A R$ suppresses GABAergic synaptic transmission. ( $A$ ) Clenbuterol decreases the frequency and amplitude of sIPSCs. (A1) An example trace with sIPSCs recorded in pyramidal cells in the absence or presence of clenbuterol. Cumulative sIPSC frequency distribution ( $A 2$, left) and amplitude distribution ( $A 3$, left) are illustrated in the recording from $A$. The summary grouped data are shown in $A 2$ (right) and $A 3$ (right). (B) Clenbuterol suppresses the amplitude of evoked IPSCs (elPSCs) and the suppression can be recovered by co-application with ICI118,551. (Left) Example traces with elPSCs were recorded, and the holding potential was $-80 \mathrm{mV}$. (Middle) The time course of averaged eIPSC amplitude (top) and averaged $R_{\mathrm{i}}$ (bottom) of all cells before, during, and after a bath application of clenbuterol without (open circles) and with the continuous presence of the $\beta 2$-AR antagonist ICI118,551 (gray circles). (Right) The individual (filled circles) and average (bars) amplitudes of elPSCs without (Clen) and with ICI118,551 (ICI + Clen) during the application of clenbuterol. $(* *) P<0.01$. (C) Clenbuterol decreases the frequency and amplitude of miniature IPSCs (mIPSCs). An example trace with mIPSCs is shown in C1. The cumulative mIPSC frequency distribution $(C 2$, left) and amplitude distribution $(C 3$, left) are illustrated in the recording from $A$. The summary grouped data are presented in $\mathrm{C} 2$ (right) and C3 (right). (**) $P<0.01$.

During the seven CS-US pairings training, all rats showed comparable increased freezing throughout the training sessions (Fig. 7B1). Trace fear memory retention was examined $24 \mathrm{~h}$ after training. Before the tone was delivered, all rats displayed similar movements in the testing chamber $\left(F_{(2,27)}=0.0729, P>0.05\right.$, one-way ANOVA, data not shown). The clenbuterol-infused rats showed a significant increase in freezing responses during the 40 -sec trace interval compared to that of the saline-infused control rats $(P<0.01$ vs. controls; controls, $n=13$ rats; clenbuterol, $n=9$ rats) (Fig. 7B2). To determine whether clenbuterol acted through additional receptors, we co-infused clenbuterol with ICI $118551(0.1 \mu \mathrm{g} / 0.5 \mu \mathrm{L})$ into mPFC immediately after training. The co-infused rats showed a comparable freezing response to the saline-infused control rats $(P>0.05$ vs. controls; clenbuterol + ICI 118551, $n=7$ rats) (Fig. 7B2).

These results demonstrate that the activation of $\beta 2-\mathrm{AR}$ in the mPFC immediately after training enhances the consolidation of trace fear memory, thereby enhancing 24-h trace fear memory.

\section{Discussion}

The functions of the PFC are sensitive to levels of NE. Low to moderate levels of endogenously released NE exert an important influence on PFC functions. It is well documented that NE produces a beneficial influence on working memory through action at the $\alpha-2 \mathrm{~A}$ adrenoceptors in the PFC. However, the role of prefrontal cortical $\beta$-ARs, particularly $\beta 2$-AR, in synaptic plasticity and memory storage is largely unknown. In this study, we demonstrate that the activation of $\beta 2$-AR facilitates spike-timing-dependent synaptic potentiation under physiological conditions of intact GABAergic inhibition in the $\mathrm{mPFC}$, which is mediated by postsynaptic Gs-cAMP-PKA signaling and the suppression of GABAergic transmission via pre- and postsynaptic mechanisms. Furthermore, the infusion of a $\beta 2$-AR agonist directly into the mPFC immediately after training enhances trace fear memory. These results suggest that NE can exert a beneficial influence on synaptic potentiation and behavioral memory in the mPFC.

Extensive evidence has suggested that $\beta$-ARs enhance synaptic plasticity and memory consolidation through GscAMP-PKA signaling (Sara 2009; Tully and Bolshakov 2010), in which $\beta$-ARs couple to Gs, the adenylyl cyclase-stimulatory G-protein, and their activation increases intracellular cAMP, which activates cAMP-dependent PKA. Previous studies showed that the activation of $\beta 2$-AR in the cortex by clenbuterol increases cAMP levels in vivo and that this increase in cAMP is significantly reduced by the $\beta 2$-AR antagonist ICI 118551 (Ordway et al. 1987). Moreover, a behavioral study revealed 
A1
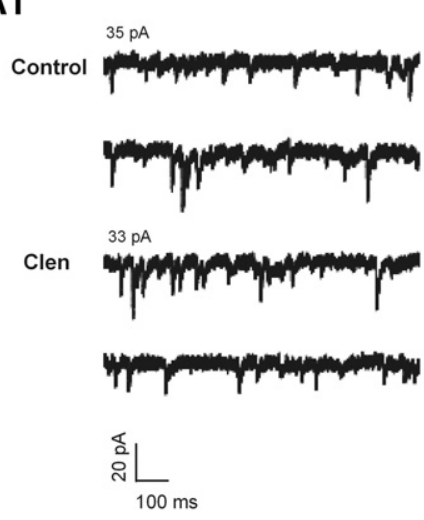

B

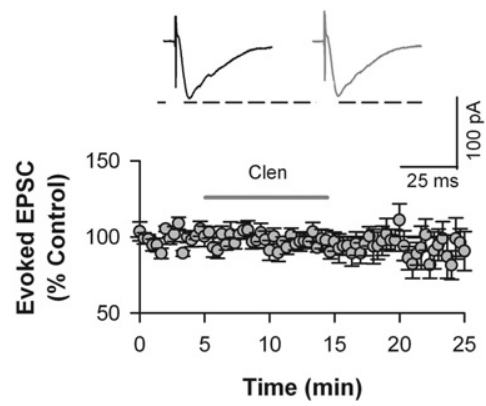

A2

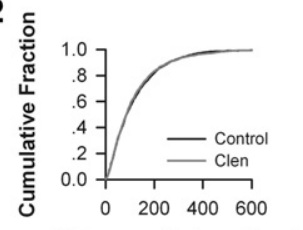
Inter-event Interval (ms)

A3

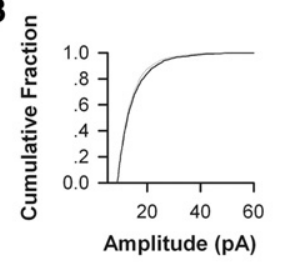

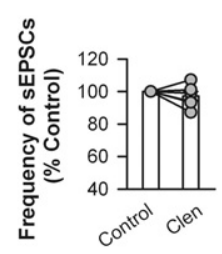
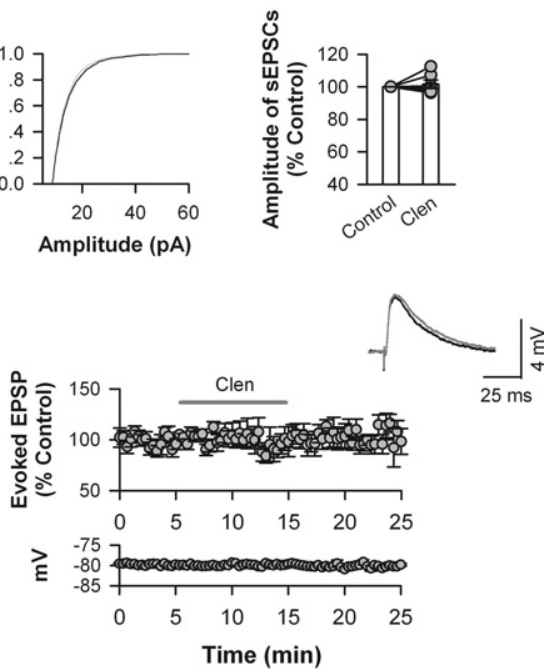

Figure 5. The activation of $\beta 2$-AR has no effect on glutamatergic transmission. $(A)$ Effect of clenbuterol on sEPSCs. (A1) An example trace with sEPSCs recorded in the absence (Control) or presence of clenbuterol (Clen). The cumulative sEPSC frequency distribution ( $A 2$, left) and amplitude distribution $(A 3$, left) are illustrated on the recording from $A 1$. The summary grouped data are presented in $A 2$ (right) and $A 3$ (right). (B) Effects of clenbuterol on evoked synaptic response. The left panel shows the time course of averaged eEPSC amplitude and the inset shows sample traces at $-70 \mathrm{mV}$ holding potential, which is averages of seven EPSCs $0-3$ min before (black) and 7-10 min after (gray) application of clenbuterol, respectively. The right panel shows the time course of averaged eEPSP slope and averaged membrane potential $(\mathrm{mV})$ of all cells before, during, and after bath application of clenbuterol and the inset shows sample traces at $-80 \mathrm{mV}$ membrane potential.

that clenbuterol enhances memory storage by coupling to adenylyl cyclase and increasing cAMP levels in the amygdala (Ferry et al. 1999). In the present study, we demonstrate that the enhancement of tLTP induced by $\beta 2$-AR activation requires an elevation of cAMP in the PFC, and the inhibition of a cAMP elevation, or its downstream PKA, decreases the facilitation of tLTP (Fig. 3). Meanwhile, tLTP facilitation requires the functioning of G protein (Fig. 3). Therefore, we show that $\beta 2$-AR can couple to Gs-cAMP-PKA signaling to enhance synaptic potentiation and memory formation. Recently, Thomas and colleagues reported that the activation of $\beta 2$-AR by zinterol or xamoterol impairs the retrieval of memory via Gi/o-coupled signaling (Schutsky et al. 2011a, b). $\beta 2$-AR has been proposed to couple to $\mathrm{Gi}$, the pertussis toxin-sensitive adenylyl cyclase-inhibitory G-protein, and this coupling can limit or prevent increases in cAMP in cardiac myocytes (Xiao et al. 1995; Daaka et al. 1997; Devic et al. 2001). This discrepancy of $\beta 2$-AR in memory processing may result from the $\beta 2$-AR activation by different types of $\beta 2$-AR agonists. Thus, $\beta 2$-AR appears to play a distinct role in memory processing via coupling with different downstream signaling, although the mechanism responsible for the recruitment of different signaling by $\beta 2-\mathrm{AR}$ is unknown.

In the PFC, noradrenergic fibers originating from the brain stem target both deep and superficial layers of the cortex (Lewis and Morrison 1989; Miner et al. 2003). Synaptic plasticity occurring in superficial layer $2 / 3$ pyramidal cells of the cortex has been proposed to correspond to the trace fear conditioning (Wu et al. 2008; Descalzi et al. 2012). LTP of central synapses is believed to magnitude but does not prevent the enhancement (Fig. 3B). However, the mechanism is unclear that the activation of $\beta 2$-AR enhances tLTP through coupling to cAMP-PKA. Several lines show that the activation of $\beta$-ARs enhance tLTP by increasing the time window for synaptic modification through coupling to cAMP-PKA signaling to increase intracellular cAMP (Lin et al. 2003; Seol et al. 2007), while the elevation of intracellular cAMP inhibits slow afterhyperpolarizaiton (sAHP). The inhibition of SAHP has been proposed to enhance tLTP, particularly in layer 2/ 3 of the mPFC (Fuenzalida et al. 2007; Zaitsev and Anwyl 2012). Therefore, a possible mechanism underlying tLTP facilitation by $\beta 2$-AR activation is sAHP inhibition, which is caused by intracellular cAMP elevation and can lead to tLTP enhancement. Furthermore, the induction of tLTP under physiological conditions with intact GABAergic circuits is highly susceptible to GABAergic inhibition (Meredith et al. 2003; Campanac and Debanne 2008). For example, tLTP occurring in the mPFC is influenced by dopaminergic input through suppressing GABAergic inhibitory circuit activities (Xu and Yao 2010), which decreases the threshold of tLTP resulting in tLTP enhancement. Hence, the suppression of GABAergic transmission is another possible mechanism underlying tLTP facilitation induced by $\beta 2$-AR activation. Indeed, our data show that clenbuterol enhancement of tLTP is partially attributable to GABAergic transmission suppression, as such inhibition can be effectively relieved by clenbuterol (Fig. 4) and the effect of clenbuterol is only partially mimicked by application of picrotoxin (Fig. 6). Altogether, our study reveals that both 

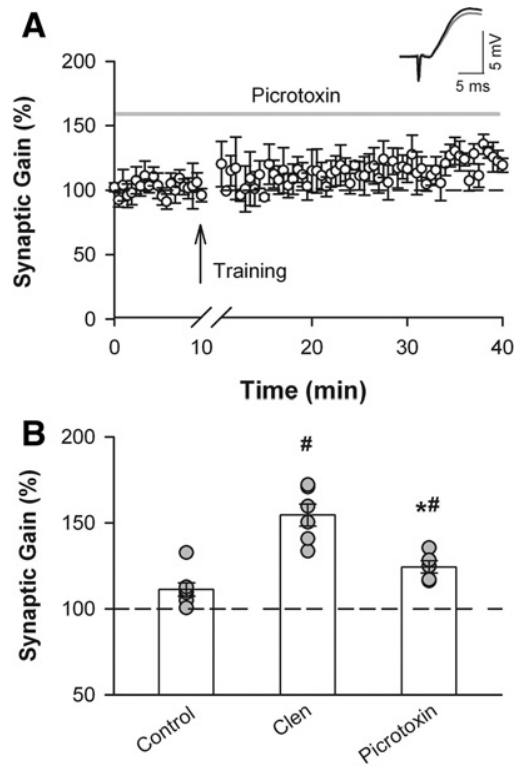

Figure 6. Suppressing GABAergic transmission partially mimics the effect of $\beta 2-A R$ activation on tLTP. ( $A$ ) tLTP is induced in the presence of pictrotoxin (indicated by gray line). The synaptic gain at 25-30 min after training is significantly above baseline $(P<0.05)$. The sample trace inset shows the averages of 11 EPSPs 5 min before (black) and 25 min after (gray) training. ( $B$ ) The group data showing tLTP in the control, clenbuterol, and pictrotoxin groups. $\left(^{*}\right) P<0.05$ vs. the clenbuterol group, $\left(\left(^{\#}\right)\right.$ $P<0.05$ vs. the control group.

postsynaptic cAMP-PKA signaling stimulation and GABAergic circuit activity suppression contribute to the tLTP facilitation following $\beta 2$-AR activation in the mPFC.

Furthermore, the mechanism by which clenbuterol suppresses GABAergic transmission is both pre- and postsynaptic. This finding is supported by, following the application of clenbuterol, a decrease in the frequency of mIPSCs, and a persistent suppression of eIPSCs in the presence of postsynaptic Rp-cAMPS or $\mathrm{PKI}_{5-24}$ (Supplemental Fig. 1), which indicates that clenbuterol can act on $\beta 2$-AR located in presynaptic GABAergic terminals to reduce GABA release. The immunostaining results further confirmed that $\beta 2$-AR is present in GABAergic terminals (Supplemental Fig. 3). Moreover, a decrease in the amplitude of mIPSCs indicates that clenbuterol can act on postsynaptic $\beta 2$-AR in pyramidal cells to suppress GABAergic transmission. Although previous studies showed that activation of $\beta$-AR facilitates GABAergic transmission in cortex (Salgado et al. 2012) and cerebellar (Sessler et al. 1989; Cheun and Yeh 1996; Saitow et al. 2000), our data support the idea that $\beta$-adrenergic modulation of GABAergic synaptic transmission depends on presynaptic interneuron subtypes (Kobayashi et al. 2009; Salgado et al. 2012). It can be speculated that clenbuterol suppresses GABAergic transmission, which likely originates from certain interneuron subtypes that primarily target layer $2 / 3$ pyramidal cells, e.g., late spiking and low-threshold spiking interneurons. The GABAergic inputs to pyramidal cells from these interneuron subtypes have been proposed to be suppressed by $\beta$-AR activation (Koyanagi et al. 2010). Furthermore, clenbuterol suppression of GABAergic transmission can be reversed by the selective $\beta 2$-AR antagonist ICI118,551 (Fig. 4B). By contrast, excitatory glutamatergic input, which is another key factor affecting LTP, was not modulated by $\beta 2$-AR activation in our study. Following the application of clenbuterol, both AMPAR-mediated response (Fig. 5) and NMDAR-mediated response remains unchanged (Supplemental Fig. 2).
The PFC has been proposed to participate in the acquisition and the storages of both trace and delayed fear memory (Sacchetti et al. 2002; Runyan et al. 2004; Gilmartin and McEchron 2005). Trace fear conditioning differs from the classic delay paradigm in that the animal must sustain attention during the trace interval to learn the CS-US association (Huerta et al. 2000; Han et al. 2003). Our results show that the post-training infusion of clenbuterol directly into the PFC enhanced trace fear memory (Fig. 7). Consistently, the intra-mPFC infusion of clenbuterol in rats or the systemic administration of clenbuterol in monkeys produces a modest improvement of cognitive functions with weak working memory performance (Ramos et al. 2008).

The present study provides the first evidence that NE can enhance tLTP via $\beta 2$-AR in the MPFC, thereby contribute to the facilitation of PFC-related memory storage. Recently, Otani and colleagues (2010) reported that NE depresses synaptic transmission with intact inhibition, while such depression can last for dozens of minutes and requires activation of $\alpha$-ARs, but not $\beta$-ARs (Marzo et al. 2010). This type of synaptic transmission depression induced by NE differs from spike-timing-dependent plasticity driving memory storage after learning. However, this type of NE-induced LTD may affect memory process by impairing the retrieval of memory or disrupting memory networks. Therefore, NE appears to exert diversity roles by acting on different types of noradrenergic receptors in the mPFC. Based on the previous study and our present study, we propose that moderate endogenously released NE promotes PFC-related memory via $\beta$-AR, which is mediated by facilitating tLTP, whereas large and sustained increases

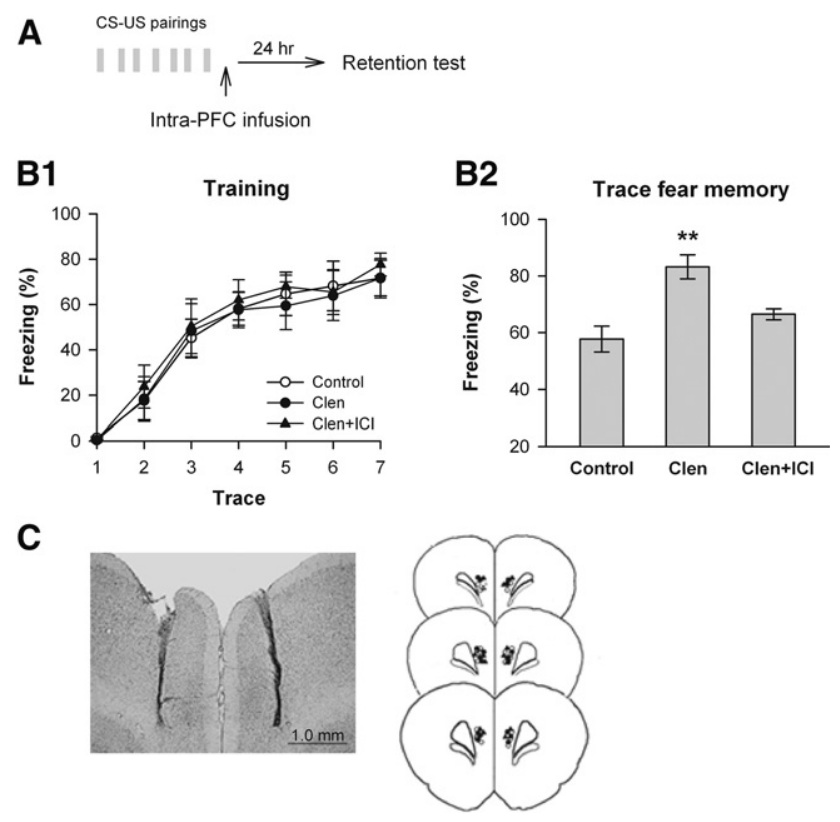

Figure 7. Post-training activation of $\beta 2-A R$ in mPFC enhances trace fear memory. $(A)$ An illustration of the sequence of post-training intra-mPFC infusions, trace-conditioning trials (CS-US pairings), and the retention test. $(B)$ Intra-mPFC infusion of clenbuterol immediately post-training enhances 24-h trace fear memory. Graphs in B1 and B2 display freezing behavior expressed as a percentage during 40-sec intervals between CS and US. The conditioning session is shown in B1. In the 24-h retention test, rats treated with clenbuterol (Clen) showed increased freezing compared to rats treated with saline (Control), and the enhancement effect is blocked by co-infusion with $\mathrm{ICI} 118551$ (Clen $+\mathrm{ICI}[B 2]) .\left({ }^{* *}\right) P<0.01$ vs. the control group. (Open circles) controls, (filled circles) clenbuterol, (filled triangles) clenbuterol $+\mathrm{ICI}$. (C) A representative coronal section showing an infusion site (left) and a reconstruction of the infusion sites in the mPFC (right). 
of endogenous NE (e.g., stress) impede PFC-related memory via $\alpha-\mathrm{AR}$, which is caused by impairing the retrieval of memory or disrupting memory networks.

In conclusion, the present study demonstrates that prefrontal cortical $\beta 2$-AR facilitates tLTP and enhances fear memory storage elicited by trace fear conditioning. Moreover, activation of $\beta 2$-AR enhances tLTP by coupling to postsynaptic cAMP-PKA cascades and suppressing inhibitory circuits with the involvement of both pre- and postsynaptic $\beta 2-\mathrm{AR}$.

\section{Materials and Methods}

\section{Electrophysiological experiment}

\section{Subjects}

Male Sprague-Dawley rats that were 4-6 wk old (100-120 g) were purchased from SLACCAS, Shanghai, China. The rats were housed under a 12-h light/dark cycle; food and water were available ad libitum. The experiments in the present study were performed in accordance with the guidelines published in the NIH Guide for the Care and Use of Laboratory Animals. Efforts were made to minimize the number of animals used and their suffering.

\section{Slice preparation}

Coronal brain slices $(300 \mu \mathrm{m})$ containing PFC were prepared using standard methods (Ji et al. 2008). The slices were transferred to a submerged recovery chamber containing oxygenated $\left(95 \% \mathrm{O}_{2}\right.$ and $\left.5 \% \mathrm{CO}_{2}\right)$ ACSF $(124 \mathrm{mM} \mathrm{NaCl}, 2.5 \mathrm{mM}$ $\mathrm{KCl}, 2.5 \mathrm{mM} \mathrm{CaCl}_{2}, 1.3 \mathrm{mM} \mathrm{MgCl} 2,26.2 \mathrm{mM} \mathrm{NaHCO}, 1.25$ $\mathrm{mM} \mathrm{NaH}_{2} \mathrm{PO}_{4}$, and $11 \mathrm{mM}$ glucose) at room temperature for at least $1 \mathrm{~h}$.

\section{Whole-cell recordings}

Whole-cell current-clamp recordings were performed using standard procedures at room temperature (Couey et al. 2007). Slices containing PFC were positioned in a perfusion chamber attached to the fixed stage of an Olympus BX51 microscope (Olympus) with infrared DIC optics for visualizing the whole-cell patchclamp recordings. eEPSPs were generated with a pulse from a stimulation isolation unit controlled by a Master- 8 pulse generator (A.M.P.I. Instruments). EPSPs were recorded from pyramidal cells in layer 2/3 using an Axon 200B amplifier (Axon Instruments), and stimulations were delivered using a bipolar tungsten stimulating electrode placed in layer $2 / 3$ approximately $100 \mu \mathrm{m}$ lateral to the recorded pyramidal cell (Fig. 1A). EPSPs were evoked every $30 \mathrm{sec}$, and the neuron membrane potentials were maintained at $-80 \mathrm{mV}$. The recording pipettes (3-5 $\mathrm{M} \Omega$ ) were filled with a solution containing $145 \mathrm{mM} \mathrm{K-gluconate,} 5$ $\mathrm{mM} \mathrm{NaCl}, 1 \mathrm{mM} \mathrm{MgCl}_{2}, 0.2 \mathrm{mM}$ EGTA, $10 \mathrm{mM}$ HEPES, $2 \mathrm{mM}$ Mg-ATP, $0.1 \mathrm{mM} \mathrm{Na}_{3}$-GTP, and $10 \mathrm{mM}$ phosphocreatine (adjusted to $\mathrm{pH} 7.2$ with $\mathrm{KOH}$ ). After obtaining stable EPSPs for $10 \mathrm{~min}$, a tLTP induction paradigm was used within 12 min after establishing the whole-cell configuration to prevent a washout effect on the tLTP induction. The slope of the initial $2.5 \mathrm{msec}$ of the EPSP was analyzed to ensure that the data reflected only the monosynaptic component of each experiment (Froemke et al. 2005). Synaptic gain was measured as the change in the average EPSP slope; namely, when a 5-min period that occurred 2530-min post-pairing was compared to the EPSP slope measured in the last $5 \mathrm{~min}$ of the 10-min baseline recordings. During the pairing period, pre- and postsynaptic stimulus pairing was repeated 50 times, with a 10 -sec interval between each pairing (Couey et al. 2007). Throughout the experiments, cell $R_{\mathrm{i}}$ was monitored by applying a $10 \mathrm{pA}, 500 \mathrm{msec}$ hyperpolarizing pulse at the end of each sweep. Data were not included in the analysis if the cell $R_{\mathrm{i}}$ varied by more than $\pm 20 \%$ during the experiment. To assess the effect of $\beta 2$-AR stimulation in these experiments, the $\beta 2$-AR agonist clenbuterol was applied during the pairing pe- riod (from $1 \mathrm{~min}$ before through $+7 \mathrm{~min}$ after the start of the 8 -min pairing protocol). For the experiments with recording pipette loading drugs, recordings were begun at least 10 min after rupturing the cell membrane. The Wilcoxon signed-rank test and Mann-Whitney $U$-test were used to assess significance in the tLTP data.

For the IPSC recordings, the pipette solution contained (in $\mathrm{mM}) 70 \mathrm{~K}$-gluconate, $70 \mathrm{KCl}, 20 \mathrm{HEPES}, 0.5 \mathrm{CaCl}_{2}$, 5.0 EGTA, and $5 \mathrm{Mg}$-ATP, and the $\mathrm{pH}$ was adjusted to 7.2 with $\mathrm{KOH}$. The cell membrane potentials were maintained at $-70 \mathrm{mV}$. The frequencies and amplitudes of sIPSC/mIPSC/sEPSC were analyzed using the Mini Analysis software package (v8.0, Synaptosoft, http://www.synaptosoft.com). Drug-induced changes in cumulative fractions of sIPSC/mIPSC/sEPSC amplitudes and interevent intervals were analyzed for statistical significance using the Kolmogorov-Smirnov (K-S) test (Mini Analysis v8.0). All grouped data were analyzed using paired or unpaired $t$-tests and a critical probability of $P<0.05$ (STATISTICA 6.0).

\section{Behavioral experiment}

\section{Subjects}

Male Sprague-Dawley rats (7-8 wk, 180-200 g) were purchased from SLACCAS, Shanghai, China. The rats were housed in plastic cages (1-2 per cage) and placed on a 12-h light/dark cycle. Food and water were provided ad libitum throughout the experiment.

\section{Surgery}

The rats were anesthetized with sodium pentobarbital $(40 \mathrm{mg} / \mathrm{kg}$ i.p.). Stainless steel guide cannulae (23-gauge) were bilaterally positioned above the PrL area of the mPFC based on the coordinates (Paxinos and Watson 1986): bregma $+3.2 \mathrm{~mm}$, lateral $\pm 0.75 \mathrm{~mm}$, and a depth of $-1.5 \mathrm{~mm}$ from the skull surface. The guide cannulae were fixed to the skull with dental cement. Dummy cannulae, cut $0.5 \mathrm{~mm}$ longer than the guide cannulae, were inserted into the guide cannulae to prevent clogging and reduce the risk of infection. The rats were provided a minimum recovery of $5 \mathrm{~d}$ before the experimental procedures were performed.

\section{Drug administration}

The $\beta 2$-AR agonist clenbuterol ( $1 \mu \mathrm{g}$ in $0.5 \mu \mathrm{L}$ saline per side) and the $\beta 2$-AR antagonist ICI 118551 ( $0.1 \mu \mathrm{g}$ in $0.5 \mu \mathrm{L}$ saline per side) were prepared as concentrated stock solutions in distilled water. For drug administration, the rats were gently held while the dummy cannulae were exchanged with 30-gauge infusion cannulae. The tip of the injection needle was $2.7 \mathrm{~mm}$ beyond that of the guide cannula, which yielded a total distance of $4.2 \mathrm{~mm}$ from the skull surface and reached to the PrL area. The drug solution was infused bilaterally with an infusion pump at a rate of $0.2 \mu \mathrm{L}$ per min. Each side of the mPFC was infused with a total volume of $0.5 \mu \mathrm{L}$ drug solution. After the infusion, the infusion cannulae were left in place for an additional 2 min to allow the drug solution to diffuse from the tip of the cannulae. The dummy cannulae were then replaced and the rats were returned to their home cages. The infusions were performed immediately after training.

\section{Behavioral procedure}

All behavioral tests were performed by an investigator who was blind to the treatment groups. A trace fear conditioning protocol, with a minor modification, was performed as previously described (Runyan et al. 2004). The animals were briefly placed in the training context (Med Associates Inc.) and provided a 120-sec habituation period. The conditioning trials began with a 10 -sec tone $(2.2$ $\mathrm{kHz}, 80 \mathrm{~dB}$, CS) followed by a 40 -sec trace period before the animal received a 0.5 -sec $(0.5 \mathrm{~mA})$ foot shock (US). The rats' freezing behavior was monitored by a camera. The percentage of freezing was measured every $1 \mathrm{sec}$ during the trace period (40 sec) after the tone. The conditioning trial was followed by a pseudo-random intertrial interval (ITI) that varied between 1 and $3 \mathrm{~min}$. The 
conditioning trial was repeated seven times during a 16-min training period.

The retention of a CS-US association was measured at $24 \mathrm{~h}$ by monitoring freezing behavior. During trace memory retention testing, the animal was placed in a novel context and provided with a 120-sec habituation period. In the absence of a foot shock, a 10-sec tone was produced followed by a varied ITI period. The retention trial was repeated four times. Only three retention trials were used for the analyses. The percentage of freezing was measured every $1 \mathrm{sec}$ during the trace period ( $40 \mathrm{sec}$ ) after the tone.

\section{Chemicals}

All reagents were purchased from Sigma-Aldrich with the exceptions of Rp-cAMPS and $\mathrm{PKI}_{5-24}$ (the PKA inhibitor fragment 5-24), which were purchased from Tocris Bioscience. All channel blockers were prepared as concentrated stock solutions in distilled water or DMSO and were either added immediately to the ACSF in working concentrations or stored at $-20^{\circ} \mathrm{C}$ for subsequent use.

\section{Immunostaining}

The rats (approximately 30-d old and $100 \mathrm{~g}$ ) were deeply anesthetized with pentobarbital sodium $(45 \mathrm{mg} / \mathrm{kg}$, i.p.), and a transcardial perfusion was performed with $300 \mathrm{~mL}$ of $37^{\circ} \mathrm{C}$ saline followed by $200 \mathrm{~mL}$ of $4 \%$ ice-cold paraformaldehyde (PFA) dissolved in phosphate-buffered saline (PBS, pH 7.4). The brains were removed and fixed for $2 \mathrm{~h}$ in PFA at $4^{\circ} \mathrm{C}$. The brains were then placed in $30 \%(\mathrm{w} / \mathrm{v})$ sucrose solution. Coronal sections $(35$ $\mu \mathrm{m})$ were cut using a cryostat (Leica CM900). The sections were rinsed with $0.01 \mathrm{M}$ PBS and incubated in a solution of $0.5 \%$ Triton-X in PBS for 30 min followed by $10 \%$ normal goat serum (Invitrogen Immunodetection) for $2 \mathrm{~h}$ at room temperature.

For double immunofluorescence, the sections were incubated in a mixture of rabbit anti- $\beta 2$-AR (1:25; Catalogue No. SC-9042, Santa Cruz) and mouse anti-CaMKII (1:120, Catalogue No. MAB8699, Lot No. LV1377413; Chemicon International), which is a pyramidal cell marker (Muller et al. 2006). The primary antibodies were diluted in goat serum and incubated for $48 \mathrm{~h}$ at $4^{\circ} \mathrm{C}$. After a 48-h incubation, the sections were rinsed with PBS and the appropriate secondary antibody was applied. Fluorescent secondary antibodies (whole-IgG affinity-purified antibodies, Alexa Fluor 568 goat anti-rabbit, and Alexa Fluor 488 goat antimouse, from Jackson ImmunoResearch Laboratories) were applied to the tissues at a dilution of 1:400 in normal blocking serum for 2 $\mathrm{h}$ at $4^{\circ} \mathrm{C}$.

The immunolabeled sections were examined and all images were obtained using a confocal laser-scanning microscope system (Olympus FV 1000). Twelve-bit images were captured at a resolution of $1024 \times 1024$ pixels using $20 \times$ PlanApo and $40 \times$ PlanApo immersion (1.2 NA) objectives. Immunoreactivity was examined under a condition of optimal resolution. The pinhole diameter was set to $105 \mu \mathrm{m}$ to significantly reduce the contribution of cytoplasmic fluorescence. Z-sectioning was performed at 1 to $2 \mu \mathrm{m}$ intervals, and stacks of optical sections on the $z$-axis were acquired. Confocal photomicrographs were further processed using Adobe Photoshop. The pictures were not modified except for adjustments of scaling, levels, brightness, and contrast. No immunolabeling was observed in the control slices in which the primary antibody was omitted. A multi-tracking configuration was used to eliminate crosstalk between the fluorescent detection channels.

\section{Data analysis and statistics}

Data are expressed as the mean \pm SEM in all cases, with $P<0.05$ indicating significance. Data between two groups were statistically compared using $t$-tests, while data among the groups were analyzed using a one-way analysis of variance (ANOVA) with planned comparisons as post hoc analyses using STATISTICA (StatSoft).

\section{Acknowledgments}

This work was supported by grants from the National Natural Science Foundation of China (31271171, 30990263, and 30821002 to B.-M.L.; 31121061 and 30700218 to X.-H.Z.) and the Ministry of Science and Technology of China (2011CBA00406 to B.-M.L.).

\section{References}

Arnsten AF, Goldman-Rakic PS. 1985. $\alpha 2$-adrenergic mechanisms in prefrontal cortex associated with cognitive decline in aged nonhuman primates. Science 230: 1273-1276.

Arnsten AF, Jentsch JD. 1997. The $\alpha-1$ adrenergic agonist, cirazoline, impairs spatial working memory performance in aged monkeys. Pharmacol Biochem Behav 58: 55-59.

Arnsten AF, Cai JX, Goldman-Rakic PS. 1988. The $\alpha-2$ adrenergic agonist guanfacine improves memory in aged monkeys without sedative or hypotensive side effects: Evidence for $\alpha-2$ receptor subtypes. J Neurosci 8: $4287-4298$.

Berridge CW, Waterhouse BD. 2003. The locus coeruleus-noradrenergic system: Modulation of behavioral state and state-dependent cognitive processes. Brain Res 42: 33-84

Bi G, Poo M. 2001. Synaptic modification by correlated activity: Hebb's postulate revisited. Annu Rev Neurosci 24: 139-166.

Birnbaum S, Gobeske KT, Auerbach J, Taylor JR, Arnsten AF. 1999. A role for norepinephrine in stress-induced cognitive deficits: $\alpha$-1-adrenoceptor mediation in the prefrontal cortex. Biol Psychiatry 46: 1266-1274.

Bliss TV, Collingridge GL. 1993. A synaptic model of memory: Long-term potentiation in the hippocampus. Nature 361: 31-39.

Campanac E, Debanne D. 2008. Spike timing-dependent plasticity: A learning rule for dendritic integration in rat CA1 pyramidal neurons. J Physiol 586: 779-793.

Cheun JE, Yeh HH. 1996. Noradrenergic potentiation of cerebellar Purkinje cell responses to GABA: Cyclic AMP as intracellular intermediary. Neuroscience 74: 835-844.

Connor SA, Wang YT, Nguyen PV. 2011. Activation of $\beta$-adrenergic receptors facilitates heterosynaptic translation-dependent long-term potentiation. J Physiol 589: 4321-4340.

Couey JJ, Meredith RM, Spijker S, Poorthuis RB, Smit AB, Brussaard AB, Mansvelder HD. 2007. Distributed network actions by nicotine increase the threshold for spike-timing-dependent plasticity in prefrontal cortex. Neuron 54: 73-87.

Daaka Y, Luttrell LM, Lefkowitz RJ. 1997. Switching of the coupling of the B2-adrenergic receptor to different $\mathrm{G}$ proteins by protein kinase $\mathrm{A}$. Nature 390: $88-91$.

Descalzi G, Li XY, Chen T, Mercaldo V, Koga K, Zhuo M. 2012. Rapid synaptic potentiation within the anterior cingulate cortex mediates trace fear learning. Mol Brain 5: 6.

Devic E, Xiang Y, Gould D, Kobilka B. 2001. $\beta$-adrenergic receptor subtype-specific signaling in cardiac myocytes from $\beta(1)$ and $\beta(2)$ adrenoceptor knockout mice. Mol Pharmacol 60: 577-583.

Dias R, Robbins TW, Roberts AC. 1997. Dissociable forms of inhibitory control within prefrontal cortex with an analog of the Wisconsin Card Sort Test: Restriction to novel situations and independence from "on-line" processing. J Neurosci 17: 9285-9297.

Edelmann E, Lessmann V. 2012. Dopamine modulates spike timing-dependent plasticity and action potential properties in CA1 pyramidal neurons of acute rat hippocampal slices. Front Synaptic Neurosci 3: 6.

Ferry B, Roozendaal B, McGaugh JL. 1999. Basolateral amygdala noradrenergic influences on memory storage are mediated by an interaction between $\beta$ - and $\alpha 1$-adrenoceptors. J Neurosci 19: 5119-5123.

Flugge G, Ahrens O, Fuchs E. 1997. $\beta$-adrenoceptors in the tree shrew brain. I. Distribution and characterization of [125I]iodocyanopindolol binding sites. Cell Mol Neurobiol 17: 401-415.

Franowicz JS, Arnsten AF. 1998. The $\alpha$-2a noradrenergic agonist, guanfacine, improves delayed response performance in young adult rhesus monkeys. Psychopharmacology 136: 8-14.

Franowicz JS, Kessler LE, Borja CM, Kobilka BK, Limbird LE, Arnsten AF. 2002. Mutation of the $\alpha 2 \mathrm{~A}$-adrenoceptor impairs working memory performance and annuls cognitive enhancement by guanfacine. $J$ Neurosci 22: 8771-8777.

Froemke RC, Poo MM, Dan Y. 2005. Spike-timing-dependent synaptic plasticity depends on dendritic location. Nature 434: 221-225.

Fuenzalida M, Fernandez de Sevilla D, Buno W. 2007. Changes of the EPSP waveform regulate the temporal window for spike-timing-dependent plasticity. J Neurosci 27: 11940-11948.

Fuster JM. 2003. Cortex and mind: unifying cognition, pp. 155-164. Oxford University Press, New York. 
Fuster JM, Bodner M, Kroger JK. 2000. Cross-modal and cross-temporal association in neurons of frontal cortex. Nature 405: 347-351.

Gelinas JN, Nguyen PV. 2005. $\beta$-adrenergic receptor activation facilitates induction of a protein synthesis-dependent late phase of long-term potentiation. J Neurosci 25: 3294-3303.

Gilmartin MR, Helmstetter FJ. 2010. Trace and contextual fear conditioning require neural activity and NMDA receptordependent transmission in the medial prefrontal cortex. Learn Mem 17: $289-296$.

Gilmartin MR, McEchron MD. 2005. Single neurons in the medial prefrontal cortex of the rat exhibit tonic and phasic coding during trace fear conditioning. Behav Neurosci 119: 1496-1510.

Goldman-Rakic PS. 1987. Circuitry of the primate prefrontal cortex and the regulation of behavior by representational memory. In Handbook of physiology V (ed. Plum F), pp. 373-417. American Physiological Society, Bethesda.

Han CJ, O'Tuathaigh CM, van Trigt L, Quinn JJ, Fanselow MS, Mongeau R, Koch C, Anderson DJ. 2003. Trace but not delay fear conditioning requires attention and the anterior cingulate cortex. Proc Natl Acad Sci 100: $13087-13092$.

Huerta PT, Sun LD, Wilson MA, Tonegawa S. 2000. Formation of temporal memory requires NMDA receptors within CA1 pyramidal neurons. Neuron 25: 473-480.

Introini-Collison IB, Miyazaki B, McGaugh JL. 1991. Involvement of the amygdala in the memory-enhancing effects of clenbuterol. Psychopharmacology 104: 541-544.

Jay TM, Burette F, Laroche S. 1995. NMDA receptor-dependent long-term potentiation in the hippocampal afferent fibre system to the prefrontal cortex in the rat. Eur J Neurosci 7: 247-250.

Ji JZ, Wang XM, Li BM. 2003. Deficit in long-term contextual fear memory induced by blockade of $\beta$-adrenoceptors in hippocampal CA1 region. Eur J Neurosci 17: 1947-1952.

Ji XH, Cao XH, Zhang CL, Feng ZJ, Zhang XH, Ma L, Li BM. 2008. Pre- and postsynaptic $\beta$-adrenergic activation enhances excitatory synaptic transmission in layer V/VI pyramidal neurons of the medial prefrontal cortex of rats. Cereb Cortex 18: 1506-1520.

Kalaria RN, Andorn AC, Tabaton M, Whitehouse PJ, Harik SI, Unnerstall JR. 1989. Adrenergic receptors in aging and Alzheimer's disease: Increased $\beta$ 2-receptors in prefrontal cortex and hippocampus. J Neurochem 53: $1772-1781$.

Kandel ER. 2001. The molecular biology of memory storage: A dialog between genes and synapses. Biosci Rep 21: 565-611.

Katsuki H, Izumi Y, Zorumski CF. 1997. Noradrenergic regulation of synaptic plasticity in the hippocampal CA1 region. J Neurophysiol 77: 3013-3020.

Kobayashi M, Kojima M, Koyanagi Y, Adachi K, Imamura K, Koshikawa N. 2009. Presynaptic and postsynaptic modulation of glutamatergic synaptic transmission by activation of $\alpha(1)$ - and $\beta$-adrenoceptors in layer $\mathrm{V}$ pyramidal neurons of rat cerebral cortex. Synapse 63: 269-281.

Koyanagi Y, Yamamoto K, Oi Y, Koshikawa N, Kobayashi M. 2010. Presynaptic interneuron subtype- and age-dependent modulation of GABAergic synaptic transmission by $\beta$-adrenoceptors in rat insular cortex. J Neurophysiol 103: 2876-2888.

Laroche S, Jay TM, Thierry AM. 1990. Long-term potentiation in the prefrontal cortex following stimulation of the hippocampal CA1/ subicular region. Neurosci Lett 114: 184-190.

Lemon N, Aydin-Abidin S, Funke K, Manahan-Vaughan D. 2009. Locus coeruleus activation facilitates memory encoding and induces hippocampal LTD that depends on $\beta$-adrenergic receptor activation. Cereb Cortex 19: 2827-2837.

Lewis DA, Morrison JH. 1989. Noradrenergic innervation of monkey prefrontal cortex: A dopamine- $\beta$-hydroxylase immunohistochemical study. J Comp Neurol 282: 317-330.

Li BM, Mao ZM, Wang M, Mei ZT. 1999. $\alpha$-2 adrenergic modulation of prefrontal cortical neuronal activity related to spatial working memory in monkeys. Neuropsychopharmacology 21: 601-610.

Lin YW, Min MY, Chiu TH, Yang HW. 2003. Enhancement of associative long-term potentiation by activation of $\beta$-adrenergic receptors at CA1 synapses in rat hippocampal slices. J Neurosci 23: 4173-4181.

Magee JC, Johnston D. 1997. A synaptically controlled, associative signal for Hebbian plasticity in hippocampal neurons. Science 275: 209-213.

Mao ZM, Arnsten AF, Li BM. 1999. Local infusion of an $\alpha-1$ adrenergic agonist into the prefrontal cortex impairs spatial working memory performance in monkeys. Biol Psychiatry 46: 1259-1265.

Markram H, Lubke J, Frotscher M, Sakmann B. 1997. Regulation of synaptic efficacy by coincidence of postsynaptic APs and EPSPs. Science 275: $213-215$

Marzo A, Bai J, Caboche J, Vanhoutte P, Otani S. 2010. Cellular mechanisms of long-term depression induced by noradrenaline in rat prefrontal neurons. Neuroscience 169: 74-86.
Meredith RM, Floyer-Lea AM, Paulsen O. 2003. Maturation of long-term potentiation induction rules in rodent hippocampus: Role of GABAergic inhibition. J Neurosci 23: 11142-11146.

Miller EK, Cohen JD. 2001. An integrative theory of prefrontal cortex function. Annu Rev Neurosci 24: 167-202.

Miner LH, Schroeter S, Blakely RD, Sesack SR. 2003. Ultrastructural localization of the norepinephrine transporter in superficial and deep layers of the rat prelimbic prefrontal cortex and its spatial relationship to probable dopamine terminals. J Comp Neurol 466: 478-494.

Miranda MI, Sabath E, Nunez-Jaramillo L, Puron-Sierra L. 2011. $\beta$-Adrenergic receptors in the insular cortex are differentially involved in aversive vs. incidental context memory formation. Learn Mem 18: 502-507.

Muller JF, Mascagni F, McDonald AJ. 2006. Pyramidal cells of the rat basolateral amygdala: Synaptology and innervation by parvalbuminimmunoreactive interneurons. J Comp Neurol 494: 635-650.

O'Dell TJ, Connor SA, Gelinas JN, Nguyen PV. 2010. Viagra for your synapses: Enhancement of hippocampal long-term potentiation by activation of $\beta$-adrenergic receptors. Cell Signal 22: 728-736.

Ordway GA, O'Donnell JM, Frazer A. 1987. Effects of clenbuterol on central $\beta-1$ and $\beta-2$ adrenergic receptors of the rat. J Pharmacol Exp Ther 241: $187-195$.

Paxinos G, Watson C. 1986. The rat brain in stereotaxic coordinates. Academic Press, San Diego, CA.

Qian H, Matt L, Zhang M, Nguyen M, Patriarchi T, Koval OM, Anderson ME, He K, Lee HK, Hell JW. 2012. $\beta 2$-Adrenergic receptor supports prolonged $\theta$ tetanus-induced LTP. J Neurophysiol 107: 2703-2712.

Ramos BP, Colgan LA, Nou E, Arnsten AF. 2008. $\beta 2$ adrenergic agonist, clenbuterol, enhances working memory performance in aging animals. Neurobiol Aging 29: 1060-1069.

Runyan JD, Moore AN, Dash PK. 2004. A role for prefrontal cortex in memory storage for trace fear conditioning. J Neurosci 24: $1288-1295$.

Sacchetti B, Baldi E, Lorenzini CA, Bucherelli C. 2002. Differential contribution of some cortical sites to the formation of memory traces supporting fear conditioning. Exp Brain Res 146: 223-232.

Saitow F, Satake S, Yamada J, Konishi S. 2000. $\beta$-adrenergic receptor-mediated presynaptic facilitation of inhibitory GABAergic transmission at cerebellar interneuron-Purkinje cell synapses. J Neurophysiol 84: 2016-2025.

Salgado H, Garcia-Oscos F, Martinolich L, Hall S, Restom R, Tseng KY, Atzori M. 2012. Pre- and postsynaptic effects of norepinephrine on gamma-aminobutyric acid-mediated synaptic transmission in layer $2 / 3$ of the rat auditory cortex. Synapse 66: 20-28.

Sara SJ. 2009. The locus coeruleus and noradrenergic modulation of cognition. Nat Rev 10: 211-223.

Sara SJ, Segal M. 1991. Plasticity of sensory responses of locus coeruleus neurons in the behaving rat: Implications for cognition. Prog Brain Res 88: $571-585$.

Schutsky K, Ouyang M, Castelino CB, Zhang L, Thomas SA. 2011a. Stress and glucocorticoids impair memory retrieval via $\beta 2$-adrenergic, $\mathrm{Gi} / \mathrm{O}-$ coupled suppression of cAMP signaling. J Neurosci 31: $14172-14181$.

Schutsky K, Ouyang M, Thomas SA. 2011b. Xamoterol impairs hippocampus-dependent emotional memory retrieval via Gi/ o-coupled $\beta 2$-adrenergic signaling. Learn Mem 18: 598-604.

Seol GH, Ziburkus J, Huang S, Song L, Kim IT, Takamiya K, Huganir RL, Lee HK, Kirkwood A. 2007. Neuromodulators control the polarity of spike-timing-dependent synaptic plasticity. Neuron 55: 919-929.

Sessler FM, Mouradian RD, Cheng JT, Yeh HH, Liu WM, Waterhouse BD. 1989. Noradrenergic potentiation of cerebellar Purkinje cell responses to GABA: Evidence for mediation through the $\beta$-adrenoceptor-coupled cyclic AMP system. Brain Res 499: 27-38.

Sjostrom PJ, Nelson SB. 2002. Spike timing, calcium signals and synaptic plasticity. Curr Opin Neurobiol 12: 305-314.

Straube T, Korz V, Balschun D, Frey JU. 2003. Requirement of $\beta$-adrenergic receptor activation and protein synthesis for LTP-reinforcement by novelty in rat dentate gyrus. J Physiol 552: 953-960.

Tronel S, Feenstra MG, Sara SJ. 2004. Noradrenergic action in prefrontal cortex in the late stage of memory consolidation. Learn Mem 11: $453-458$.

Tsvetkov E, Carlezon WA, Benes FM, Kandel ER, Bolshakov VY. 2002. Fear conditioning occludes LTP-induced presynaptic enhancement of synaptic transmission in the cortical pathway to the lateral amygdala. Neuron 34: 289-300.

Tully K, Bolshakov VY. 2010. Emotional enhancement of memory: How norepinephrine enables synaptic plasticity. Mol Brain 3: 15 .

Wang M, Ramos BP, Paspalas CD, Shu Y, Simen A, Duque A, Vijayraghavan S, Brennan A, Dudley A, Nou E, et al. 2007. $\alpha 2 \mathrm{~A}$-adrenoceptors strengthen working memory networks by inhibiting cAMP-HCN channel signaling in prefrontal cortex. Cell 129: $397-410$. 
Wu LJ, Zhang XH, Fukushima H, Zhang F, Wang H, Toyoda H, Li BM, Kida S, Zhuo M. 2008. Genetic enhancement of trace fear memory and cingulate potentiation in mice overexpressing $\mathrm{Ca}^{2+} /$ calmodulindependent protein kinase IV. Eur J Neurosci 27: 1923-1932.

Xiao RP, Ji X, Lakatta EG. 1995. Functional coupling of the $\beta 2$-adrenoceptor to a pertussis toxin-sensitive $G$ protein in cardiac myocytes. Mol Pharmacol 47: 322-329.

Xu TX, Yao WD. 2010. D1 and D2 dopamine receptors in separate circuits cooperate to drive associative long-term potentiation in the prefrontal cortex. Proc Natl Acad Sci 107: 16366-16371.
Zaitsev AV, Anwyl R. 2012. Inhibition of the slow afterhyperpolarization restores the classical spike timing-dependent plasticity rule obeyed in layer 2/3 pyramidal cells of the prefrontal cortex. J Neurophysiol 107: $205-215$.

Zhang JC, Lau PM, Bi GQ. 2009. Gain in sensitivity and loss in temporal contrast of STDP by dopaminergic modulation at hippocampal synapses. Proc Natl Acad Sci 106: 13028-13033.

Received January 16, 2013; accepted in revised form February 20, 2013. 


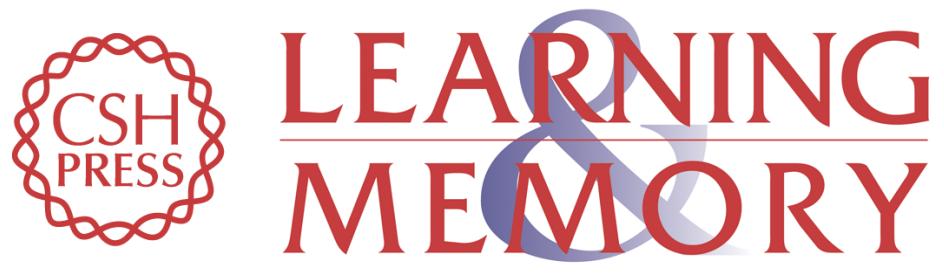

\section{Activation of $\beta 2$-adrenoceptor enhances synaptic potentiation and behavioral memory via cAMP-PKA signaling in the medial prefrontal cortex of rats}

Hou-Cheng Zhou, Yan-Yan Sun, Wei Cai, et al.

Learn. Mem. 2013, 20:

Access the most recent version at doi:10.1101//m.030411.113

Supplemental http://learnmem.cshlp.org/content/suppl/2013/04/17/20.5.274.DC1

Material

References This article cites 76 articles, 24 of which can be accessed free at: http://learnmem.cshlp.org/content/20/5/274.full.html\#ref-list-1

License

Email Alerting Receive free email alerts when new articles cite this article - sign up in the box at the Service top right corner of the article or click here. 